\title{
Traduire
}

Une autre perspective sur r tr traduction

Revue française de la traduction

234 | 2016

La traduction, un sport de haut niveau

\section{Idéologie et traductologie}

Sous la direction d'Astrid Guillaume

\section{Morgane Boëdec}

\section{(2) OpenEdition}

Journals

Édition électronique

URL : http://journals.openedition.org/traduire/821

DOI : 10.4000/traduire.821

ISSN : 2272-9992

Éditeur

Société française des traducteurs

Édition imprimée

Date de publication : 15 juin 2016

Pagination : 92-94

ISSN : 0395-773X

Référence électronique

Morgane Boëdec, « Idéologie et traductologie », Traduire [En ligne], 234 | 2016, mis en ligne le 01 octobre 2016, consulté le 24 septembre 2020. URL : http://journals.openedition.org/traduire/821 ; DOI :

https://doi.org/10.4000/traduire.821 


\section{Compte rendu d'ouvrage Idéologie et traductologie Sous la direction d'Astrid Guillaume}

\section{Morgane Boëdec}

\section{L'idéologie là où on ne l'attend pas...}

Cet ouvrage, préfacé par Marianne Lederer et François Rastier, est un recueil des communications présentées lors du colloque international éponyme organisé à l'Université Paris Sorbonne (Paris IV), Maison de la recherche, les 1er et 2 février 2016 par James ARCHIBALD (Université McGill, Canada), Lynne FRANJIÉ (Université Lille 3), Mathieu GUIDĖRE (Université Toulouse 2) et Astrid GUILLAUME (Université Paris Sorbonne).

S'il est désormais reconnu que le traducteur n'est pas transparent, dans quels contextes, pourquoi et comment présente-t-il l'information source au lecteur cible, lecteur modèle de sa culture mais non de la culture de l'auteur? L'ouvrage se propose d'aborder la manière dont l'idéologie influence la traduction, avec des présentations concernant l'arabe, le bulgare, l'espagnol, le grec, l'italien, le japonais, le polonais, le portugais, le turc et le russe. Chaque auteur étudie un ou plusieurs cas précis, les contextualisant - tant au niveau de l'époque et de sa charge sociopolitique, que des contraintes (auto-)imposées des traducteurs, souvent en fonction des attentes des récepteurs du message. Nous parcourons ainsi des univers allant de l'idéologie et la traduction du religieux en arabe à la traduction des silences en grec, en découvrant des exemples de sexisme langagier en polonais ou d'orientation de la lecture par le traducteur avant même la rencontre du lecteur avec le texte, en turc.

Marianne Lederer précise que " [l] nature de l'idéologie est duelle : d'une part, l'idéologie affichée des partis politiques, des religions, des philosophes, de l'autre une idéologie diffuse, sorte de vision du monde déterminée par les conditions socio-historiques de l'époque (...)(1) ". Par exemple, les nombreuses traductions bulgares de Hamlet entre 1891 et 2012 n'ont pas été produites dans les mêmes circonstances, la lecture du texte anglais n'étant pas passée sous

(1) GUILLAUME Astrid (dir.), 2016, Idéologie et traductologie, Paris, éditions L'Harmattan, p. 11. 
la même loupe idéologique selon l'époque. Ainsi, on pourrait presque dater les différentes traductions par la seule observation des choix terminologiques, qui révèlent l'environnement sociopolitique.

De même, en arabe, l'étude de la traduction simultanée de discours politiques sur la chaîne de télévision Al-Jazeera révèle que les traducteurs modulent, divergent, effacent et atténuent la charge idéologique des locuteurs étrangers, créant dès lors eux-mêmes un discours, fortement idéologique, répondant aux attentes à la fois du public et de la chaîne. Tel que le confirme Rastier dans sa préface, " une traduction $\mathrm{p}$ [eut] être dite idéologique quand elle renonce à sa mission critique et ne prend pas la distance nécessaire : elle concrétise alors un système de croyances préétabli (2), "

L'exemple illustré par l'article " Idéologie et traductions de la guerre en espagnol " porte sur les choix exercés en matière de toponymie. Les Argentins ont leurs Malvinas, et les Britanniques les Falkland Islands, mais dès lors que l'on choisit l'un ou l'autre terme - peu importe la langue de communication -, le message est idéologique, le parti est pris.

L'article sur la traduction de la compassion en japonais traite, entre autres, de la réaction des Japonais au lendemain des attentats à Charlie Hebdo en janvier 2015 à Paris. L'auteur y aborde "la responsabilité de la traduction, comme acte de "faire le pont" entre deux mondes hétérogènes(3) " et la tâche du traducteur qui doit " s'assurer que le contexte nécessaire soit bien disponible au public cible(4) ", soulignant que la rapidité de transmission des informations aujourd'hui ne permet pas toujours leur contextualisation immédiate. Le public cible n'étant pas outillé pour comprendre le sens des événements (ici la vague déferlante de soutien à l'hebdomadaire), il n'a pas immédiatement suivi ce mouvement de compassion, ce dernier lui étant culturellement, idéologiquement, inaccessible.

Pour conclure, s'il semble désormais évident que, dans la pratique, la traduction n'est pas neutre et le traducteur n'est pas indépendant, cette compilation de communications souligne que la question de l'idéologie en traduction est présente dans toutes les langues, de même que dans l'ensemble des domaines de traduction. Et l'idéologie étant toujours datée et contextualisée, il est intéressant de remarquer que les traductions sont, tout comme les textes source, marquées du sceau des choix terminologiques et stylistiques opérés au moment de leur publication. Ainsi, de la même manière que les explications de texte doivent évoluer au fil du temps pour permettre au lectorat de comprendre les éléments qui entourent le texte en question, les traductions sont revues et mises au goût du jour pour les replacer en contexte, en fonction de l'évolution de la langue.
(2) Ibid., p. 7.
(3) Ibid., p. 187.
(4) Ibidem. 
Cet ouvrage est d'autant plus intéressant qu'il couvre une grande diversité de langues et de spécialités. Nous soulignons que l'anglais ne fait pas partie des propositions retenues pour le colloque et l'ouvrage, peut-être pour laisser la place à des langues qui font moins souvent l'objet d'études, mais jouissent tout de même d'un lectorat avide de nouvelles recherches.

morgane@sustainabletranslations.fr

Idéologie et traductologie

Sous la direction d'Astrid Guillaume - Préfaces de Marianne Lederer et François Rastier Éditions L'Harmattan

Février 2016

ISBN : 978-2-343-08338-4 